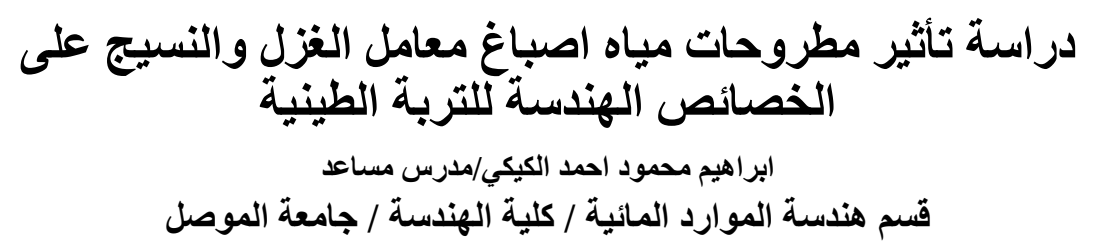

يتناول هذا البحث دراسة تأثير مياه الاصباغ على الخواص الهندسية للتربة الطينية الاتتفاخية

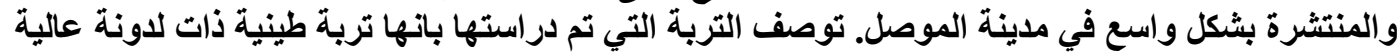
( CH ) من معامل الغزل والنسيج في مدينة الموصل ملئل

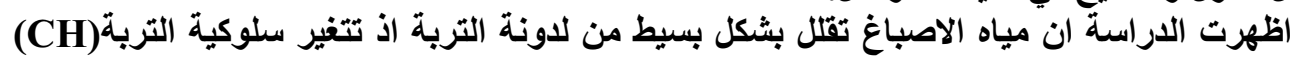

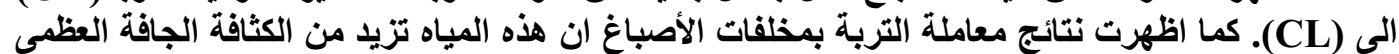

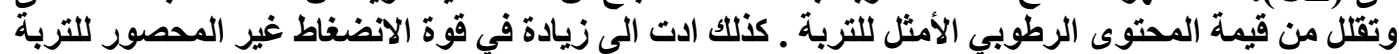

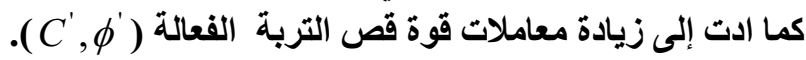

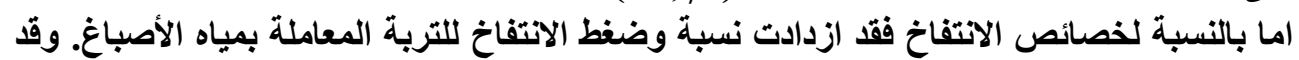

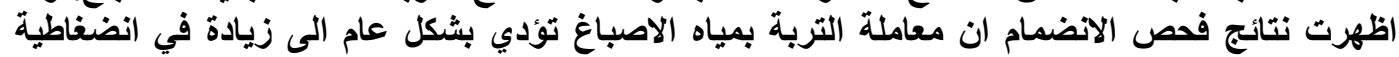

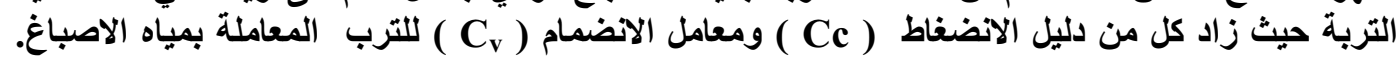

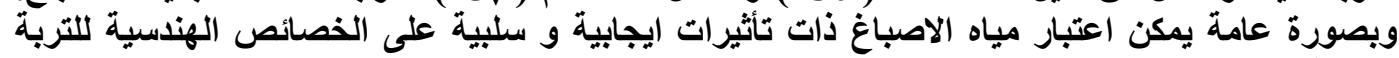
الطينية.

\title{
A STUDY OF THE EFFECT OF DYES WASTE WATER OF TEXTILE ON THE ENGINEERING PROPERTIES OF CLAYEY SOIL
}

\author{
Ibrahim M. Al-kiki
}

College of Engg. Mosul Univ.

\section{ABSTRACT}

This stady deals with the effect of waste from textiles dyeing operation on the engineering properties of Expansive clayey soil .The tested soil was obtained from of Al- Yarmook district-Mosul-City, which be described as light brown stiff clay, an inorganic type with high plasticity (CH) , It contains $(38 \%)$ clay size particles $(\leq 0.002 \mathrm{~mm})$. The soil was treated with one Types of industrial waters, Taken from Textile Manufactories Directorate in Mosul city.

The Results, showed that the industrial waters caused little reduction in the liquid limit and slight increment in the plastic index. The effect of industrial waters addition on the compaction characteristics, showed that an increase in the maximum dry density and decreace of the optimum moisture content were occured. As well As the industrial waters increased the unconfined compressive srrength and the shear strength parameters $\left(\phi^{\prime}\right)$ $\left(C^{\prime}\right)$.

The study, showed that the swelling percentage and swelling pressure increase with increasing the concentration of industrial waters. On the other hand the results of consolidation test showed that the compression Index (Cc) and coefficient of consolidation ( $\mathrm{Cv}$ ) increase as the soil was treated with industrial waters. 


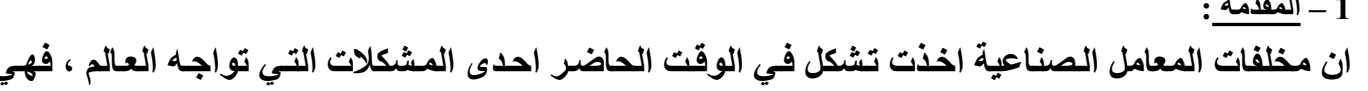

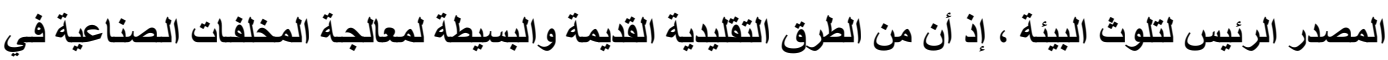

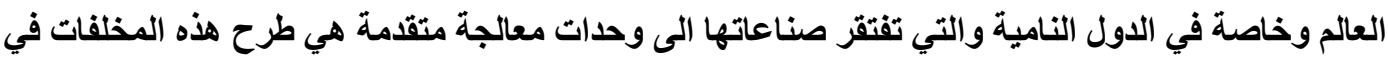

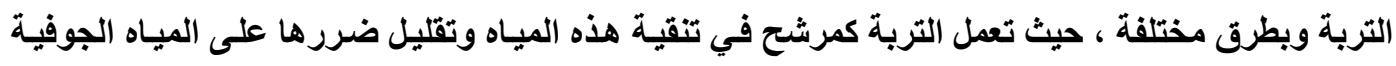

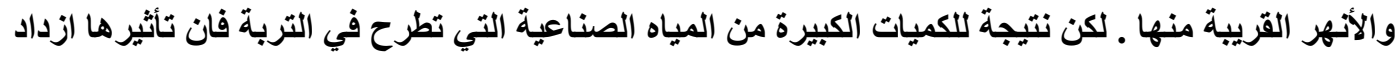

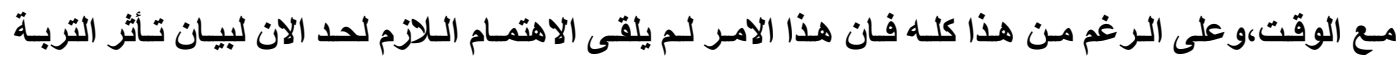
بالمخلفات.

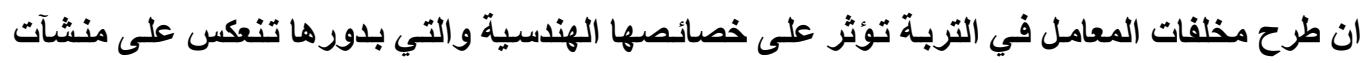

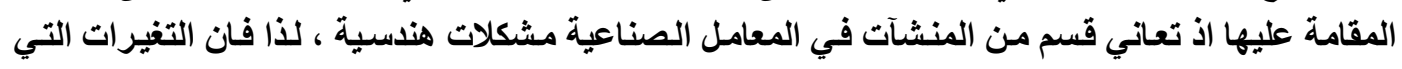

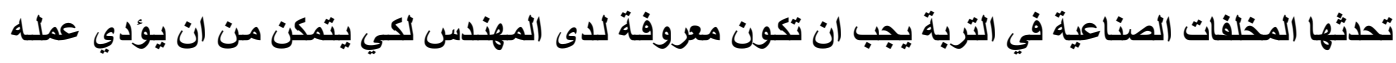

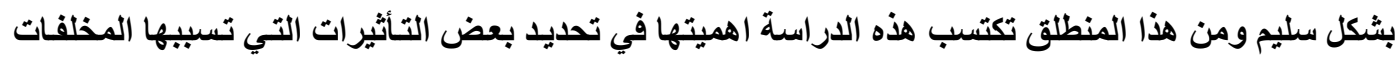

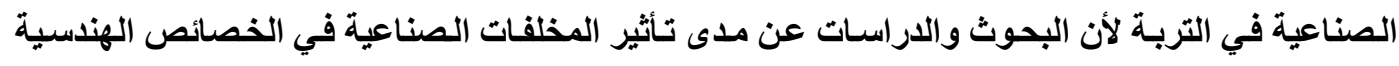

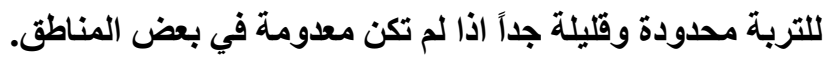

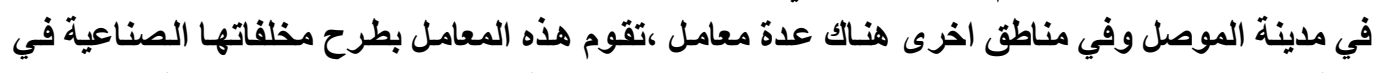

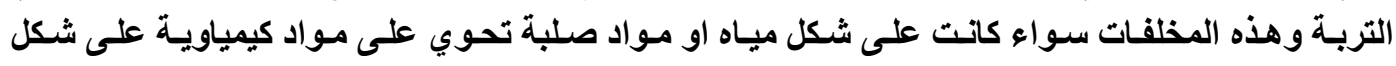

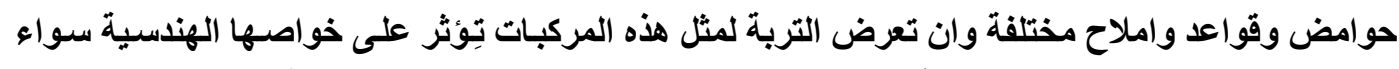

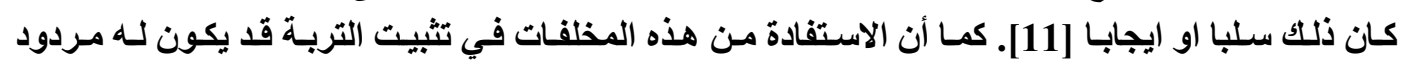

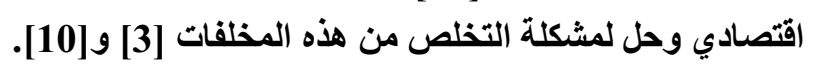

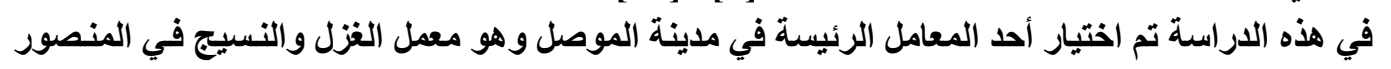

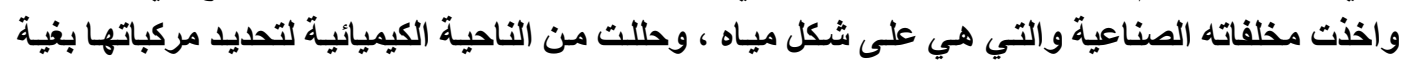

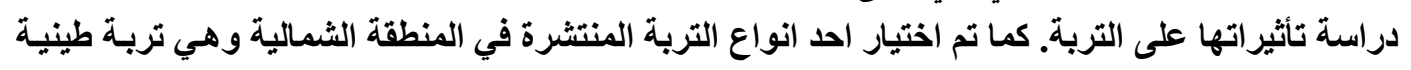
ذات خواص انتفاخية متوسطة. عوملت التربة بهذه المخلفات ( مياه الاصباغ ) كل على على حدة بطرائق وتراكيز مختلفة [11] بغيـة تحديد

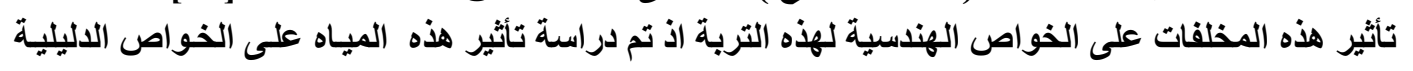

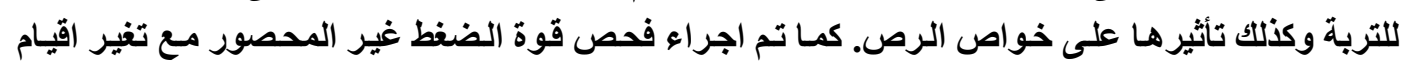

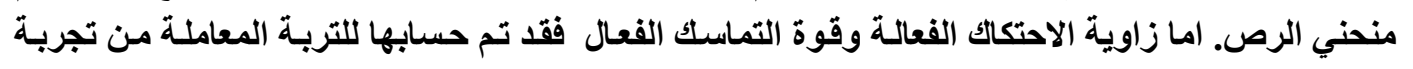
القص المباشر وباستعمال تجربة الانضمام- المبزول.

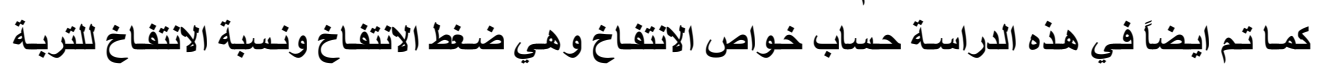

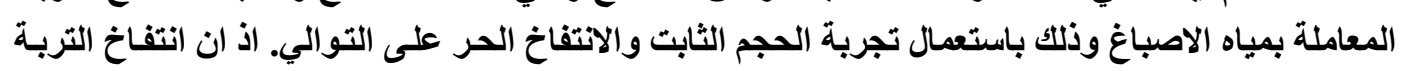

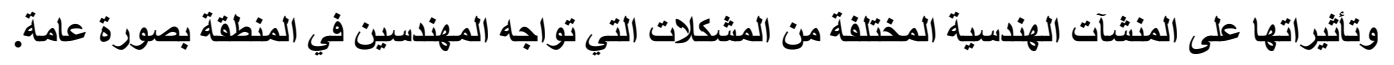

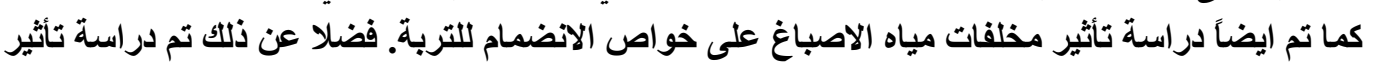

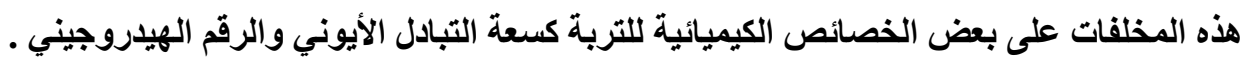




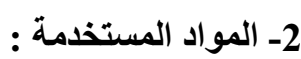

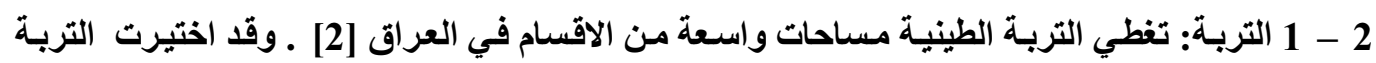

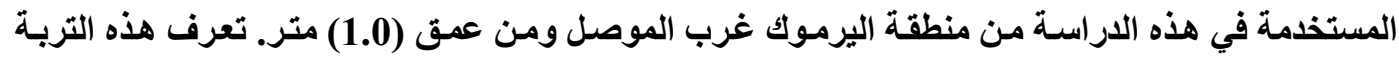

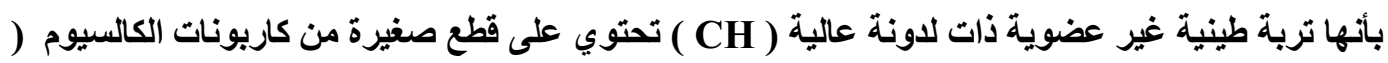

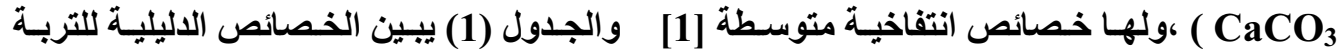

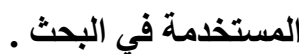

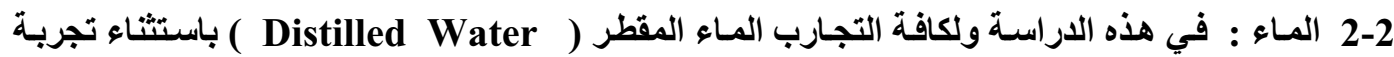

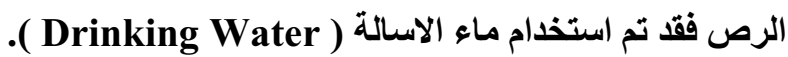
3-2 مياه الاصباغ : في هذه الدراسة تم استخدام مطروحات مياه الاصباغ للثركة العامة للصناعات القطنية

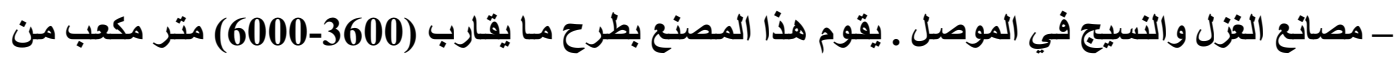

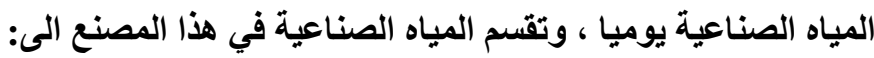

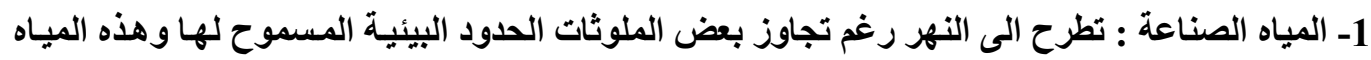

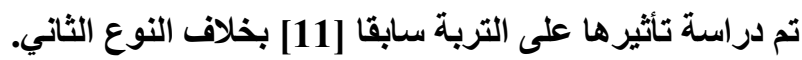

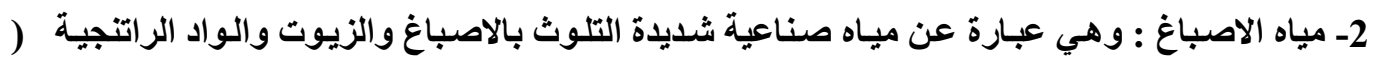

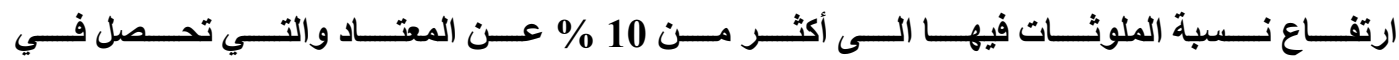

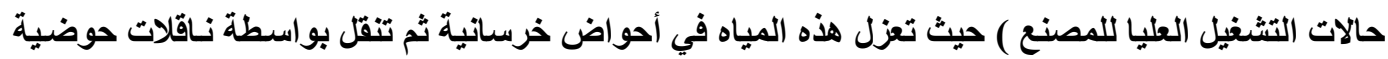
الى منطقة الطمر الصحي هناكت.

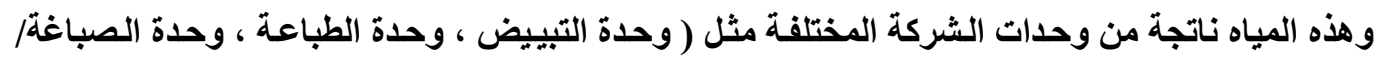

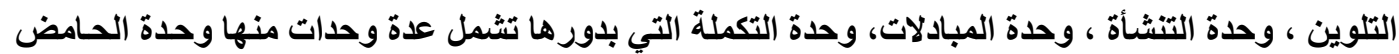

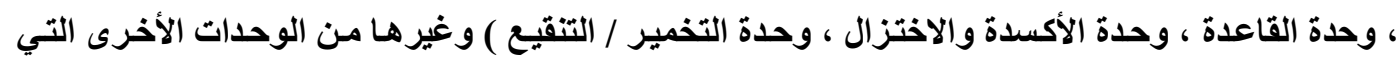

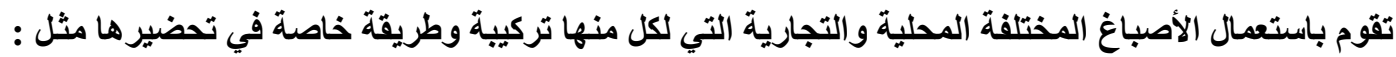

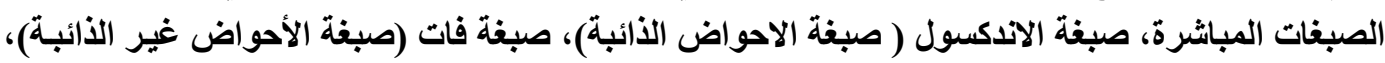
الأصباغ المتفاعلة ، صبغة البكمنت (Pigment) (الصبغة الملتصقة) .

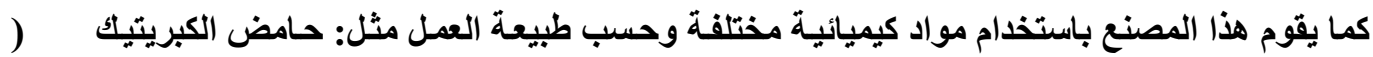
( ) ، بيروكسيد الهيــدروجين ( $\mathrm{H}_{2} \mathrm{SO}_{4}$

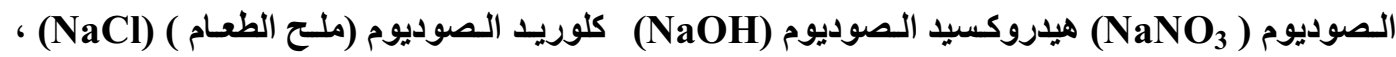
بيكاريونـات الصوديوم ( ، سليكات الصوديوم (NaOCI

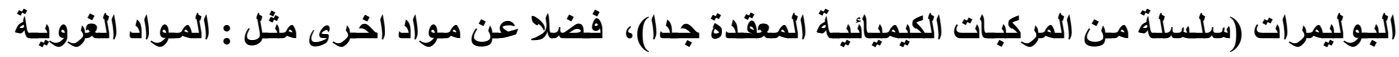

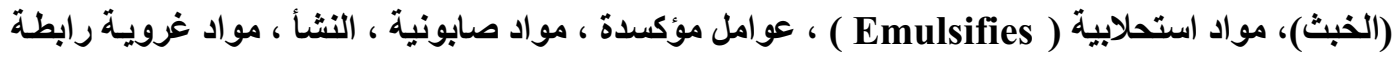
(Binders ) في تثبيت التربة كيميائيا والجدول (2) يبين التحاليل الكيميائية للمياه المستخدمة الأبريا في البحث. 


\section{1-3 مياه الاصباغ وتفاعلاتها الكيمياوية}

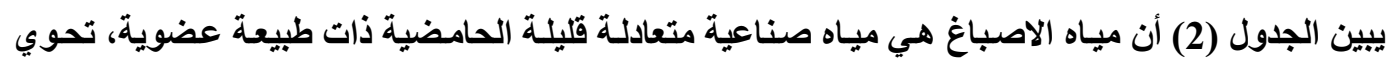

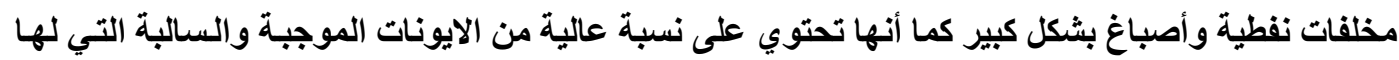

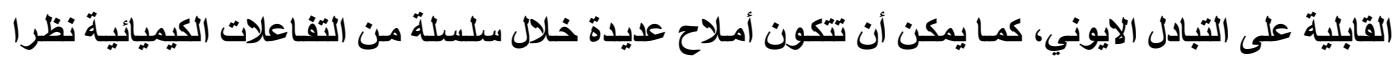

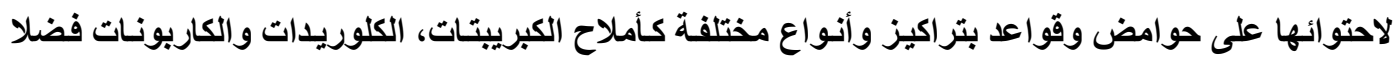
عن النترات. وأدناه بعض الامثلة عن هذه التفاعلات:

$$
\begin{array}{cc}
\mathrm{H}_{2} \mathrm{SO}_{4}+\mathrm{CaCO}_{3} \longrightarrow & \mathrm{CaSO}_{4}+\mathrm{CO}_{2}+\mathrm{H}_{2} \mathrm{O} \\
\mathrm{HCl}+\mathrm{NaOH} \longrightarrow & \mathrm{NaCl}+\mathrm{H}_{2} \mathrm{O} \\
2 \mathrm{NH}_{3}+\mathrm{CO}_{2}+\mathrm{H}_{2} \mathrm{O} & \left(\mathrm{NH}_{4}\right)_{2} \mathrm{CO}_{3} \\
\mathrm{NH}_{3}+\mathrm{HNO}_{3} \longrightarrow & \mathrm{NH}_{4} \mathrm{NO}_{3}
\end{array}
$$

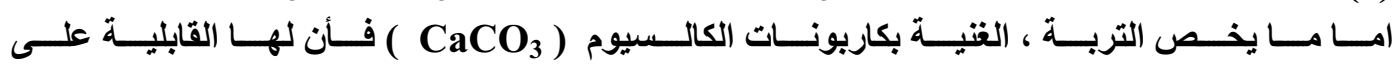
التفاعل مع مركبات المياه الصناعية اهمها تفاعلات احلال الأيونات (

$$
\text { وتنتج عن هذه التفاعلات أملاح وكما يأتي : }
$$

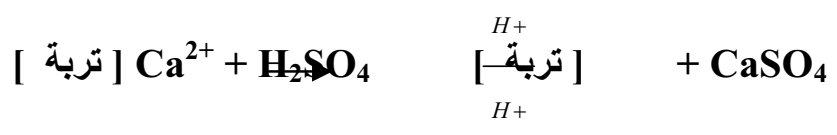

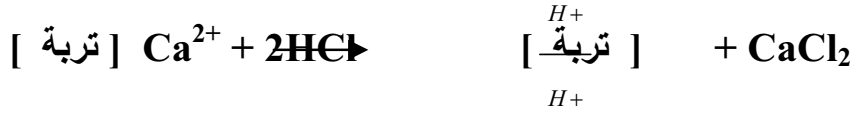

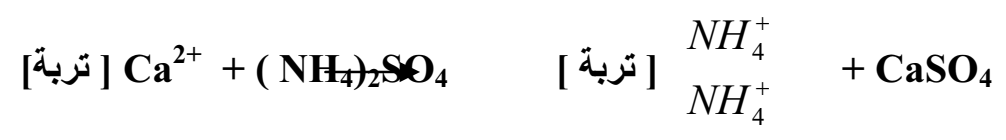

$$
\begin{aligned}
& {\left[\text { [ تربة [ [ [ [ } \left[\begin{array}{l}
\mathrm{Ca}^{2+}+\mathrm{NH}_{4}^{+} \\
\mathrm{NH}_{4}^{+}
\end{array} \quad+\mathbf{C a C l}_{\mathbf{4}} \mathbf{E l}\right.\right.}
\end{aligned}
$$

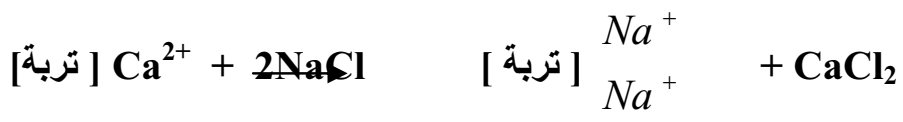

كما قد تثترك نو اتج التفاعلات السابقة مع مركبات المياه الصناعية بتفاعلات جديدة ينتج عنها مركبات (

$$
\begin{aligned}
& \mathrm{CaCl}_{2}+2 \mathrm{NH}_{3}+\mathrm{CO}_{2}+\mathrm{H}_{2} \mathrm{O} \quad \mathrm{CaCO}_{3}+2 \mathrm{NH}_{4} \mathrm{Cl}
\end{aligned}
$$

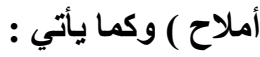

$$
\begin{aligned}
& \text { كما قد يحل ايون الفوسفات محل أيون الهيدروكسيل في معدن الطين وكما يأتي : }
\end{aligned}
$$

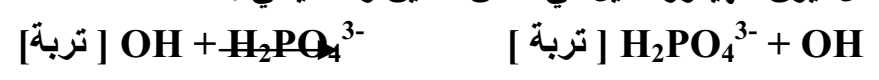

$$
\text { 2-3 تأثير مياه الاصباغ على الخصائص الاليلية للتربة }
$$

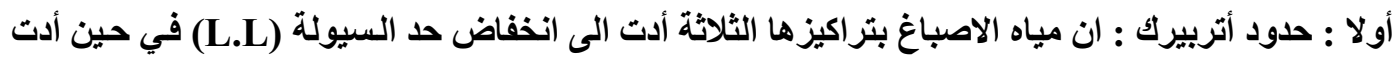

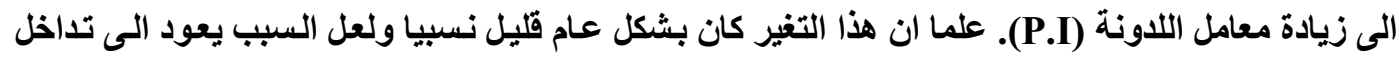

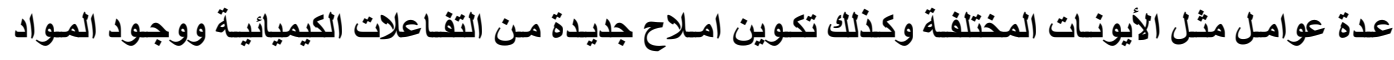

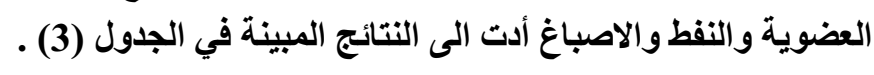




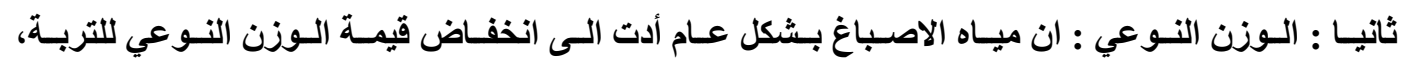

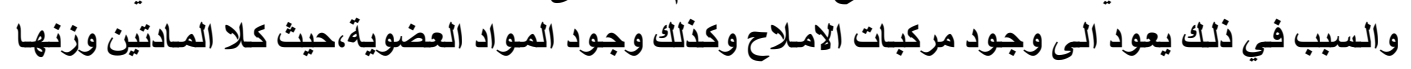

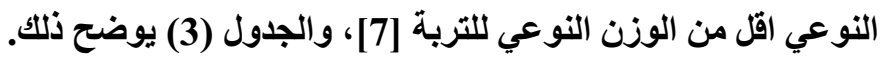

3-3 تأثير مياه الاصباغ على بعض الخصائص الكيميائية للتربة (نسبة المواد العضوية، سعة التبادل الايوني

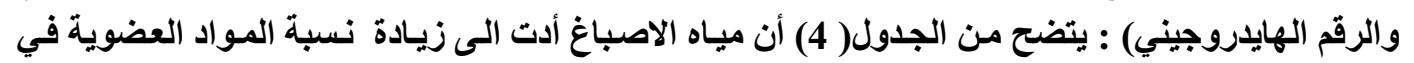

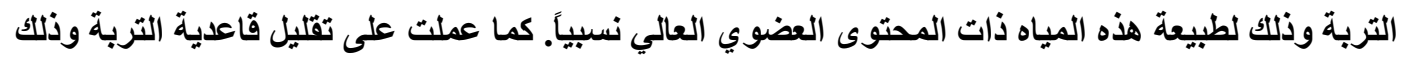

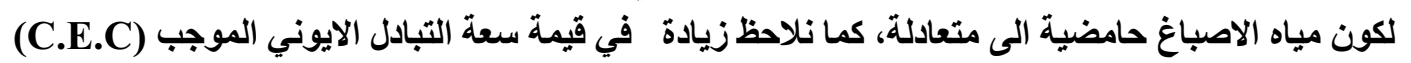

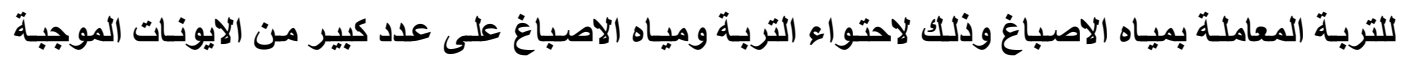
والسالبة التي لها القابلية على التبادل.

4-3 تأثير مياه الاصباغ على خواص الرص للتربة:

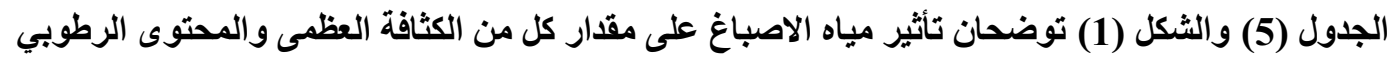
الامثل . يتضح من هذا الجدول زيادة في الكثافة الجافة العظى ( max. $\gamma_{d}$ (الامثل

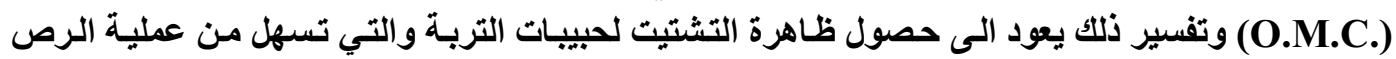

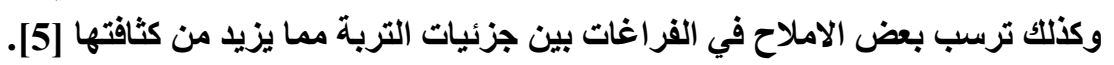

5-3 تأثير مياه الاصباغ على قوة قص التربة :

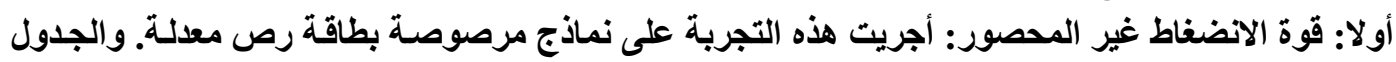

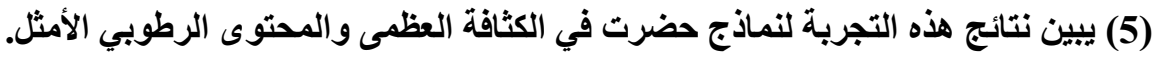

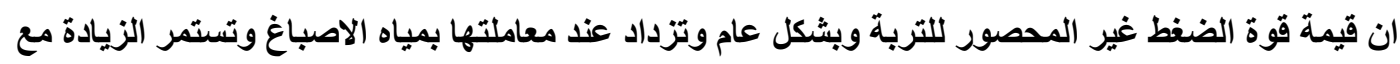

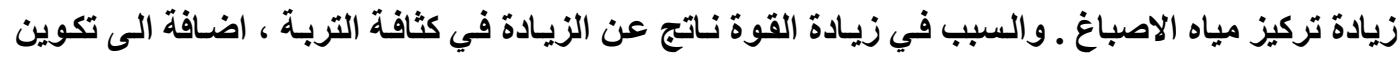

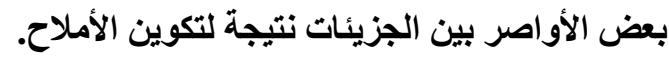

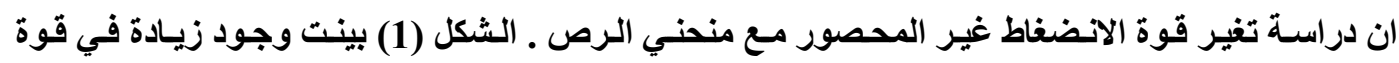

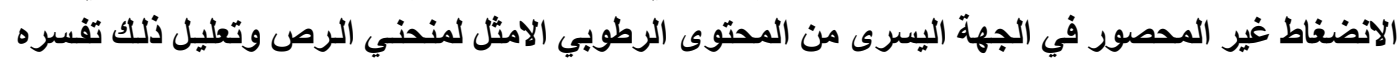

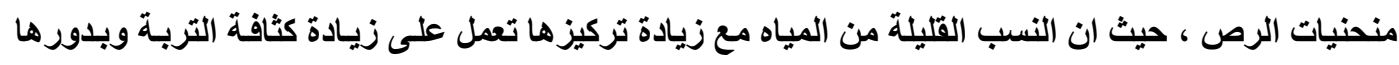

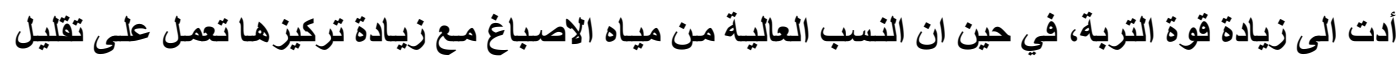

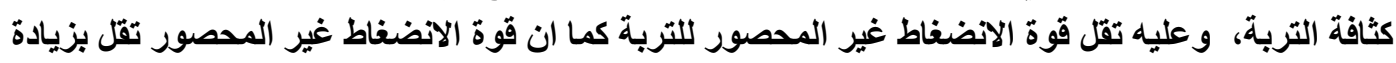

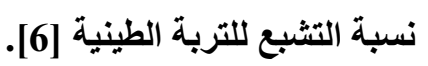

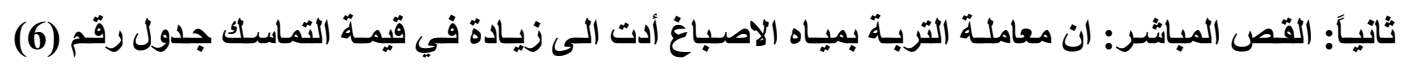

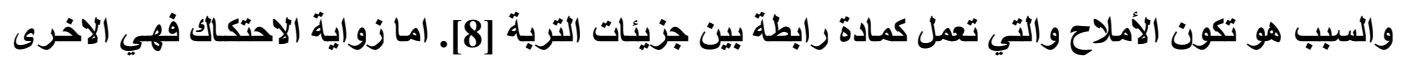

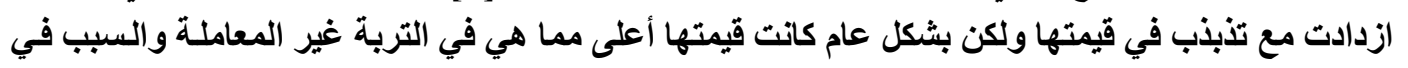

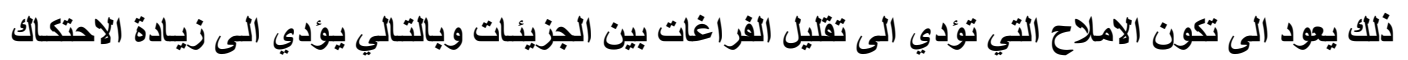

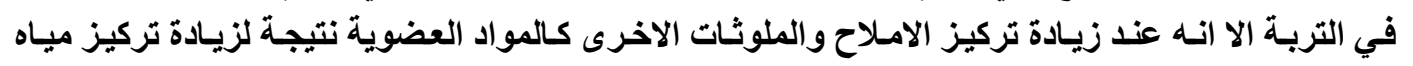

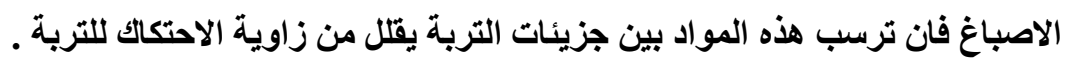
6-3 تأثير مياه الاصباغ على خصائص الأتنفاخ للتربة: 


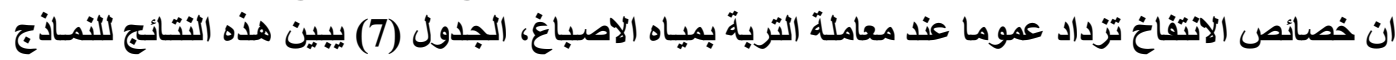

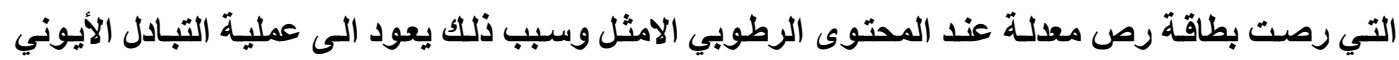

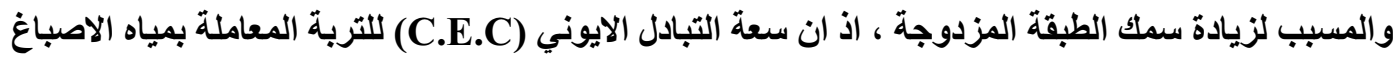

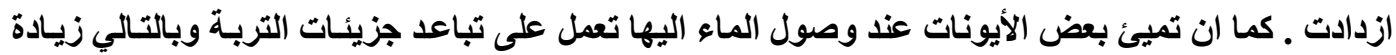

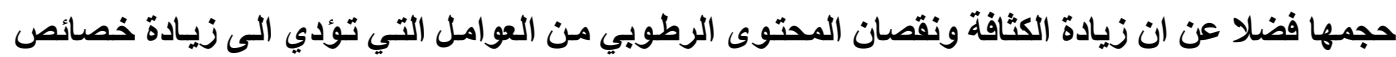

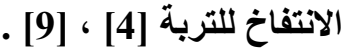

7-3 تأثير مياه الاصباغ على خصائص الانضمام للتربة :

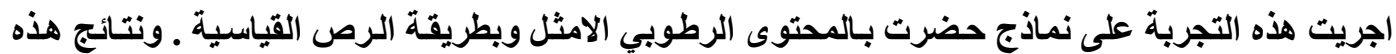

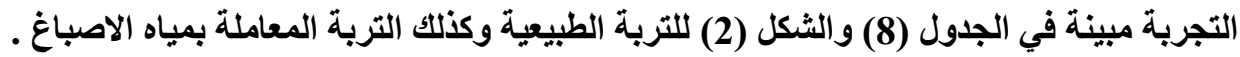

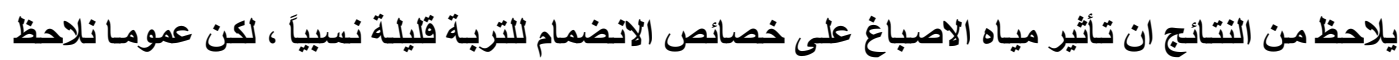

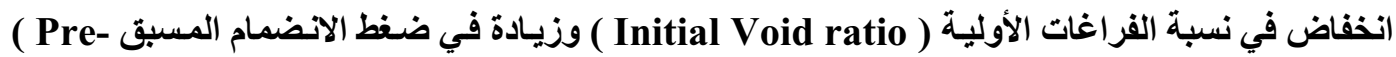
consolidation peessure "Pc" )

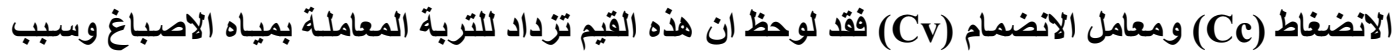

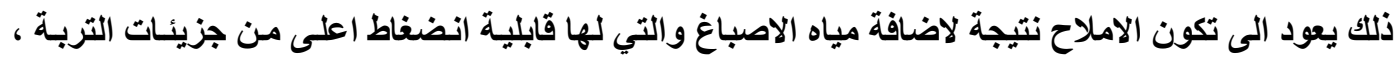

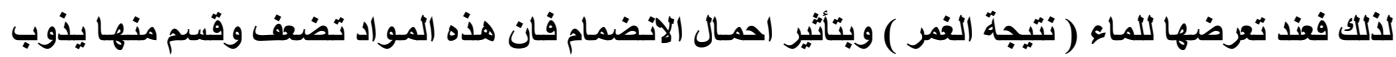

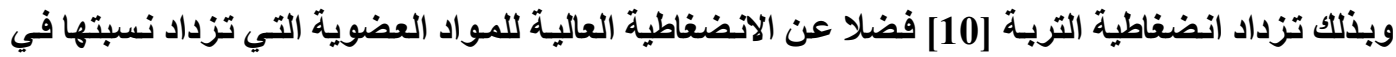

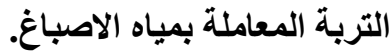

\section{من خلال هذه الدراسة تم التوصل الى أن المياه الصناعية تعمل وبشكل عام على:}

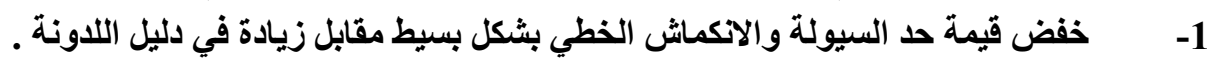

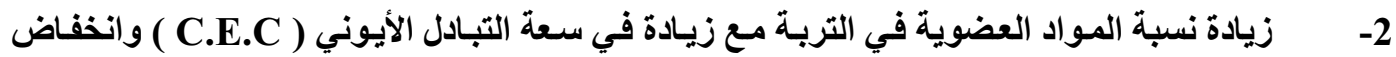
قيمة الوزن النوعي.

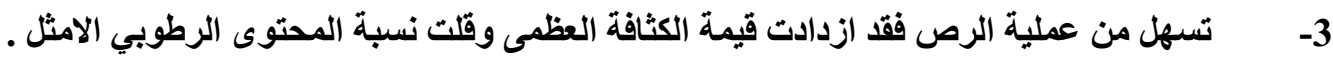

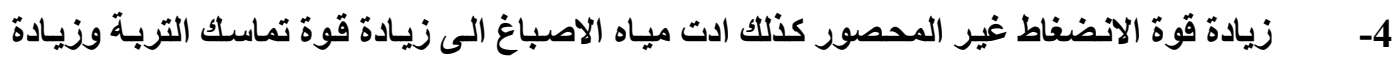
زاوية الاحتكاك.

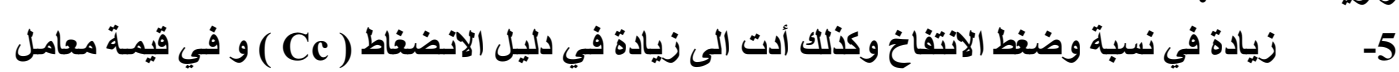
الانضمام ( Cv ). 


\begin{tabular}{|c|c|c|}
\hline 51 & حد السيولة \%(L.L) & \multirow{3}{*}{ حدود اتربرك: } \\
\hline 24 & حد اللاونة (P.L)\% & \\
\hline 27 & دليل اللاونة (P.I) & \\
\hline 14.6 & \multicolumn{2}{|c|}{ الأكماش الخطي (L.S)\% } \\
\hline 2.72 & \multicolumn{2}{|c|}{ الوزن النوعي (Gs) } \\
\hline $\mathbf{C H}$ & حسب نظام التصنيف الموحد (U.C.S. ) & \multirow{2}{*}{ |تصربة } \\
\hline $\begin{array}{c}\text { Group }=\text { A-7 } \\
\text { Sub Group= A-7-1 }\end{array}$ & $\begin{array}{r}\text { حسب نظام تصنيف الجمعية الأمريكية للطرق } \\
\text { (AASHTO C.S.) }\end{array}$ & \\
\hline 9 & الرمل \% > 0.074 ملم & \multirow{3}{*}{ التحليل الحبيبي: } \\
\hline 53 & 0.002 ملم >الغرين \% > 0.074 ملم & \\
\hline 38 & الطين (c) \% > 0.002 ملم & \\
\hline 0.71 & \multicolumn{2}{|c|}{ الفعالية (Activity) } \\
\hline 1.3 & نسبة الجبس\%\% & \multirow{6}{*}{ الكضوص } \\
\hline 1.46 & نسبة المواد العضوية\%\% & \\
\hline 0.3 & املاح الكبريتات (SO (SO & \\
\hline 2.25 & الاملاح الذائبة الكلية (T.S.S) & \\
\hline 8.54 & الرقم الهيدروجيني (PH -value) & \\
\hline 28 & $\begin{array}{r}\text { (C.E.C) سعة التبادل الايوني (meq/100mg of soil) } \\
\text { (mequ }\end{array}$ & \\
\hline
\end{tabular}


Al- Rafidain Engineering

Vol.14

No.1

2006

الجدول (2) فحوصات مياه الاصباغ المستخدمة في البحث

\begin{tabular}{|c|c|c|c|c|}
\hline |القيمة & المحددات * البيئة & 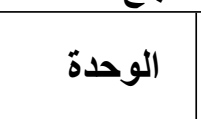 & نوع الفحص & 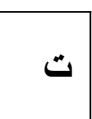 \\
\hline 350 & & 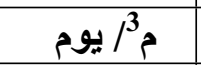 & كمية المياه المصروفة & .1 \\
\hline 6.6 & $9.4-6$ & $\mu m h o s / \mathrm{cm}$ & تركيز الهايدروجين (PH) & .2 \\
\hline 2125 & & $\mathrm{Mg} / \mathrm{l}$ & التوصيلية الكهربائية (E.C. الكر) & .3 \\
\hline 180 & & $=$ & الكاربونات (CO & .4 \\
\hline 200 & & $=$ & البيكاربونات ( & .5 \\
\hline 380 & & $=$ & (T.A.) القاعدة الكلية & .6 \\
\hline 245 & 500 & $=$ & العسرة الكلية (T.H.) & .7 \\
\hline 32 & 150 & $=$ & المغنيسيوم (Mg & .8 \\
\hline 141 & 200 & $=$ & (الكالسيوم (Ca++) & .9 \\
\hline 5 & $3>$ & $=$ & الفوسفات ( & .10 \\
\hline 98 & $600>$ & $=$ & الكلوريدات ( & .11 \\
\hline 173 & $400>$ & $=$ & الكبريتات (SO & .12 \\
\hline 7.8 & $50>$ & $=$ & النترات (NO & .13 \\
\hline 673 & 50 & $=$ & المتطلب البايوكيمياوي للأوكسجين (BOD) & .14 \\
\hline 1320 & 75 & $=$ & المتطلب الكيمياوي للأوكسجين (COD) & .15 \\
\hline 1593 & $60>$ & $=$ & المواد الصلبة (T.S.) & .16 \\
\hline 985 & $1500-1000$ & $=$ & المواد الصلبة الذائبة (T.D.S.) & .17 \\
\hline 674 & & $=$ & المواد المتطايرة)(T.V.S.) & .18 \\
\hline 507 & & $=$ & المواد الذابَة المتطايرة)(T.D.V.S.) & .19 \\
\hline $10-5$ & & $\%$ & النفط ومشتقاته & .20 \\
\hline $20-15$ & & $\%$ & الاصباغ المختلفة & .21 \\
\hline $\begin{array}{r}\text { كروم(Cr) } \\
\text { (Cr) } \\
\end{array}$ & 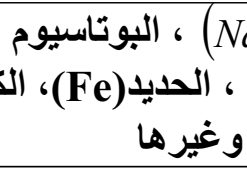 & 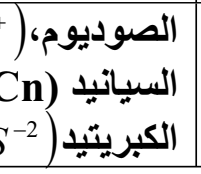 & مواد & .22 \\
\hline
\end{tabular}

* حب مواصفات منظمة الصحة العالمية (World Health Organization) (WHO) لسنة 1984م [12]. 


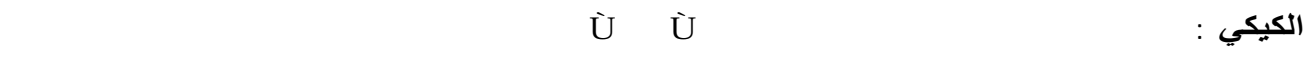

\begin{tabular}{|c|c|c|c|c|c|c|}
\hline \multirow{2}{*}{ التصنيف } & \multirow{2}{*}{ L.S.(\%) } & \multirow{2}{*}{$\mathbf{G}_{\mathbf{s}}$} & \multicolumn{3}{|c|}{ حدود اتربرك } & \multirow[t]{2}{*}{ التركيز } \\
\hline & & & P.I. (\%) & P.L. (\%) & L.L.(\%) & \\
\hline $\mathbf{C H}$ & 14.6 & 2.27 & 26 & 25 & 51.0 & $\mathbf{0}$ \\
\hline CL-CH & 14.1 & 2.703 & 28 & 22 & 50.0 & 1 \\
\hline CL & 13.8 & 2.69 & 29 & 20 & 49.0 & 2 \\
\hline CL & 13.2 & 2.674 & 27 & 20 & 47.0 & 4 \\
\hline
\end{tabular}

الجدول (4) التغير في بعض الفحوصات الكيمياوية للترب المعاملة بتر اكيز مختلفة من المياه الصناعية

\begin{tabular}{|c|c|c|c|c|}
\hline 4 & 2 & 1 & 0 & (التركير \\
\hline 3.24 & 2.5 & 1.71 & 1.46 & Organic matter content (\%) \\
\hline 7.96 & 8.23 & 8.41 & 8.54 & pH-value \\
\hline 37 & 34 & 32 & 28 & .E.C. (meq/ 100 gm of dry \\
& & & & soil) \\
\hline
\end{tabular}

الجدول (5) تأثير تركيز المياه الصناعية على خواص الرص وقوة الانضغاط غير المحصور للتربة

\begin{tabular}{|c|c|c|c|}
\hline \multirow{2}{*}{ 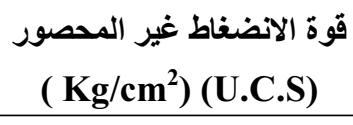 } & \multicolumn{2}{|c|}{ خواص الرص } & \multirow[t]{2}{*}{ التركيز } \\
\hline & $\left(\gamma_{d} \max .\right)\left(\mathrm{gm} / \mathbf{c m}^{3}\right)$ & O.M.C. (\%) & \\
\hline 9.7 & 1.73 & 18 & $\mathbf{0}$ \\
\hline 11 & 1.76 & 16 & 1 \\
\hline 11.8 & 1.78 & 15.5 & 2 \\
\hline 12 & 1.785 & 14.5 & 4 \\
\hline
\end{tabular}

الجدول (6) تأثير المياه الصناعية على معاملات قص التربة

\begin{tabular}{|c|c|c|}
\hline \multicolumn{2}{|c|}{ معاملات قص التربة } & \multirow[b]{2}{*}{ التركيز } \\
\hline زاوية الاحتكاك الفعالة & $\begin{array}{c}\text { التماسك الفعال } \\
C^{\prime}\left(\mathrm{Kg} / \mathbf{c m}^{2}\right)\end{array}$ & \\
\hline 30 & 0.5 & $\mathbf{0}$ \\
\hline 32 & 0.6 & 1 \\
\hline 35 & 0.75 & 2 \\
\hline 33 & 0.8 & 4 \\
\hline
\end{tabular}




\begin{tabular}{|c|c|c|c|c|}
\hline \multicolumn{5}{|c|}{ الجدول (7) تأثير مياه الاصباغ على الخصائص الانتفاخية للتربة } \\
\hline \multicolumn{4}{|c|}{ 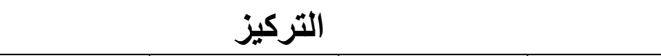 } & \multirow{2}{*}{ الخصائص } \\
\hline 4 & 2 & 1 & $\mathbf{0}$ & \\
\hline 14.5 & 15.5 & 16 & 18 & نسبة الرطوبة المثلى (\%) \\
\hline 1.785 & 1.78 & 1.76 & 1.74 & الكثافة الجافة العظمى (gm/cm³) \\
\hline 5.5 & 5.3 & 4.6 & 3.2 & نسبة الانتفاخ (\%) \\
\hline 3.57 & 3.5 & 2.8 & 1.8 & ضغط الانتفاخ (Kg/cm²) \\
\hline
\end{tabular}

\begin{tabular}{|c|c|c|c|c|}
\hline 4 & 2 & 1 & 0 & ع المعاملة \\
\hline 0.572 & 0.579 & 0.601 & 0.645 & $e_{0}$ \\
\hline 0.12 & 0.118 & 0.121 & 0.115 & $\mathrm{C}_{\mathrm{c}}$ \\
\hline 0.0265 & 0.0255 & 0.0248 & 0.0238 & $\mathrm{C}_{\mathrm{s}}$ \\
\hline 2.8 & 2.6 & 2.5 & 1.966 & $P_{c}\left(\mathrm{Kg} / \mathrm{cm}^{2}\right)$ \\
\hline 2.17 & 2.0 & 1.4 & 0.8 & $\mathrm{Cv} \times 10^{-4} \mathrm{~cm}^{2} / \mathrm{sec}$ \\
\hline 1.45 & 1.4 & 1.2 & 1.052 & $\mathrm{~K} \times 10^{-9} \mathrm{~cm} / \mathrm{sec}$ \\
\hline
\end{tabular}



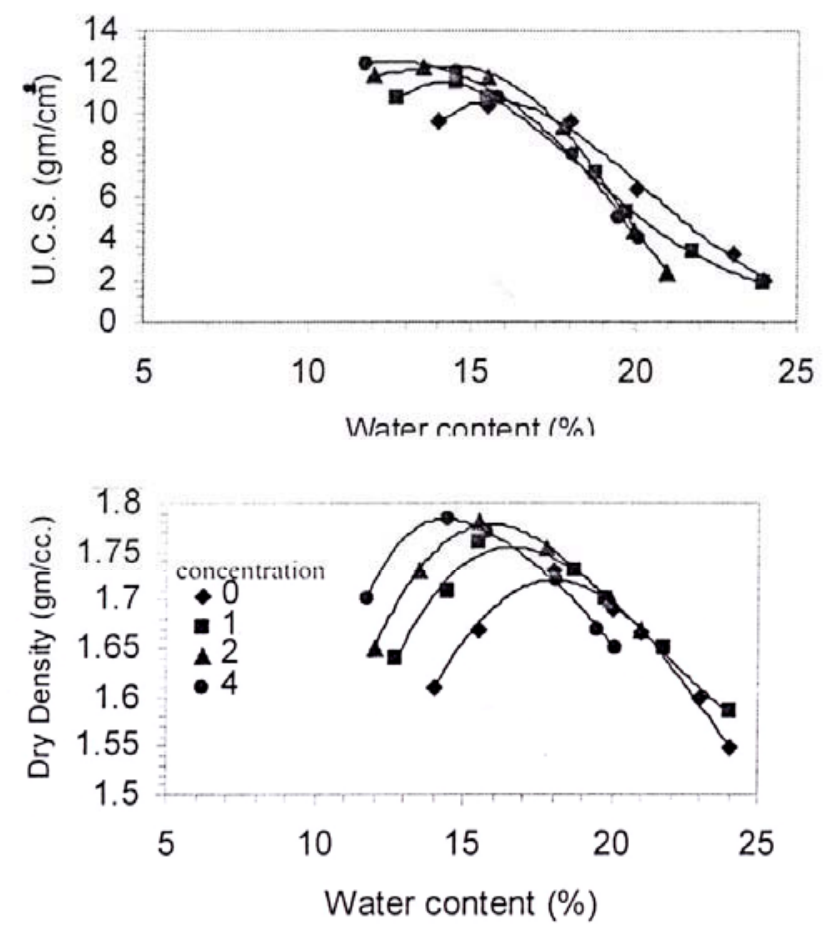

الثُكل (1) تأثير مياه الاصباغ على منحنيات الرص وقوة الانضغاط غير المحصور للتربة

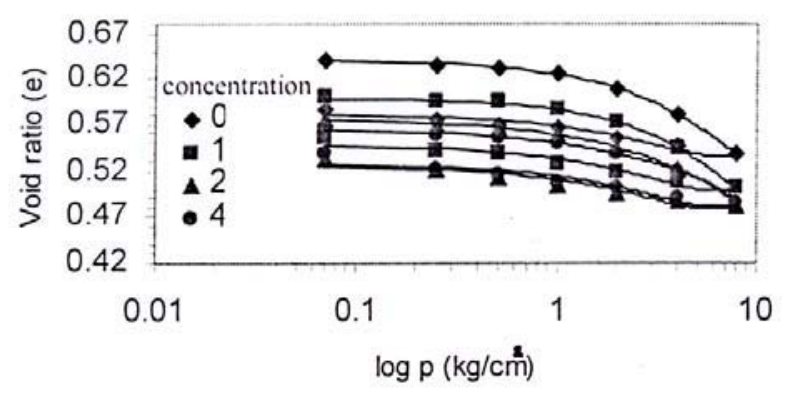

الثكل (2) منحنيات الانضمام للتربة الطبيعية و المعاملة بمياه الاصباغ 
$\begin{array}{cccc}\text { Al- Rafidain Engineering } & \text { Vol.14 } & \text { No.1 } & 2006 \\ \text { Refernces } & & & \end{array}$

1.

Al - Ashou, M. O., "Expansive Properties of the Clay in Mosul Area ", M.Sc. Thesis, Civil Engineering Department, University of Mosul , 1977.

2. Al- Layla, M. T. and Al-Ashou, M. O., " Swelling Properties of Mosul Clay ", Iraqi Conference on Engineering . ICE, Baghdad University , Engineering College, Baghdad - IRAQ, 1985.

3. Al - Shalhomi, A. Y. A., " Effect of Phospho-Gypsum on the engineering Characteristics of the Clayey Soil ", M.Sc. Thesis, Civil Engineering Department , University of Mosul, 2000.

4. Gromko, M. and Gerald, J. " Review of Expansive Soil ", Proceeding Journal of the Geo technical engineering Division, ASCE, Vol. 100, GT. 6, pp. 667 - 685, Jan., 1974.

5. Nemerow, N. L., " Industrial Water Pollution, Origins, Characteristics, and Treatment ", Addison-Wesley Publishing Company Inc. New York, 1978.

6. Peak, R. B., Hanson, W. E. and Thorburn, T.H., " Foundation Engineering ", John Wiley and Sons, $2^{\text {nd }}$ ed., 1974.

7. Thompson, E.V. and Ceckler, H.W., " Introduction to

Chemical Engineering ", Mc Graw-Hill, Inc., Ch. 6, pp. 378-388, 1981.

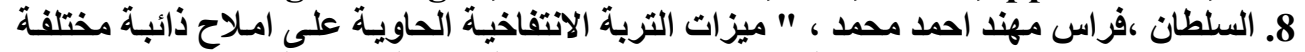

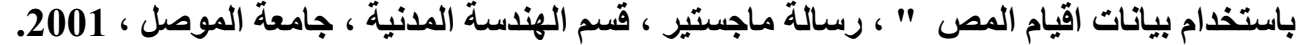

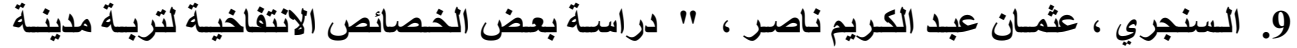

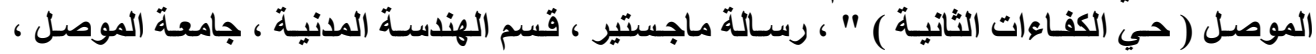

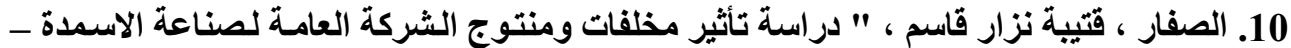

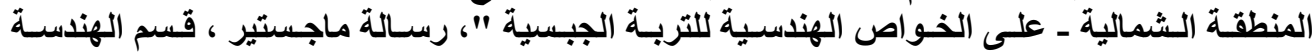

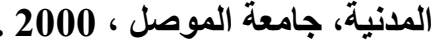

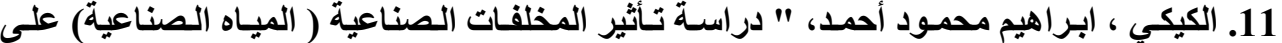

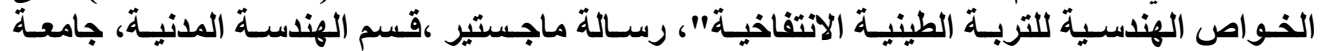

الموصل، 2001. 2012.

12. عباوي ، سعاد عبد وحسن، محمد سليمان، " الهندسة العلمية للبنـاء ( فحوصـات المـاء)"، دار

الحكمة للطباعة والنشر ، الموصل ، 1990. 